\title{
An Incentive Dynamic Programming Method for the Optimization of Scholarship Assignment
}

\author{
Di Huang, ${ }^{1}$ Yu Gu $\mathbb{D}$, ${ }^{1}$ Hans Wang, ${ }^{2}$ Zhiyuan Liu $\left(\mathbb{D},{ }^{1}\right.$ and Jun Chen $\mathbb{D}^{1}$ \\ ${ }^{1}$ Jiangsu Key Laboratory of Urban ITS, Jiangsu Province Collaborative Innovation Center of Modern Urban Traffic Technologies, \\ School of Transportation, Southeast University, China \\ ${ }^{2}$ Department of Logistics \& Maritime Studies, The Hong Kong Polytechnic University, Kowloon, Hong Kong
}

Correspondence should be addressed to Zhiyuan Liu; zhiyuanl@seu.edu.cn

Received 8 June 2018; Accepted 31 July 2018; Published 12 August 2018

Academic Editor: Xinchang Wang

Copyright (C) 2018 Di Huang et al. This is an open access article distributed under the Creative Commons Attribution License, which permits unrestricted use, distribution, and reproduction in any medium, provided the original work is properly cited.

\begin{abstract}
Scholarship assignment is an operations management problem confronting university administrators, which is traditionally solved based on administrators' personal experiences. This paper proposes an incentive method inspired by dynamic programming to replace the traditional decision-making process in the scholarship assignment. The objective is to find the optimal scholarship assignment scheme with the highest equity while accounting for both the practical constraints and the equity requirement. Moreover, with the proposed method, the scholarship assignment avoids time- and energy-consuming application processes conducted by students. A solution algorithm is used to find feasible assignment schemes by iteratively solving a series of knapsack subproblems based on dynamic programming and adjusting the monetary value of a unit score. The optimal assignment scheme can then be screened out by applying the Gini coefficient for quantifying the equity of each feasible scheme. A numerical case is investigated to illustrate the applicability of the proposed method and solution algorithm. The results indicate that the proposed method is an efficient tool to assign scholarships to students with consideration of the equity.
\end{abstract}

\section{Introduction}

Scholarships act as an important incentive and plays a crucial role in encouraging undergraduate and graduate students in universities to work hard, excel, and aim for higher education in their academic careers. It is also considered as an important component from the teaching perspective. Many researches have proved that scholarships have positive effects on students' performances in college and encourage students to seek for further education [1-3]. Different scholarships are funded by different sponsors, such as entrepreneurs, institutions, individuals, etc., who are in charge of determining the number of awardees and amount of money awarded to each recipient. Departments of universities are responsible for assigning scholarships to candidates by ranking them based on their performances in departments. However, the university administrators have no right to further divide the existing scholarships into new scholarships with smaller amounts of monetary awards. The performances of students are evaluated by the score they gained each year. The final score of a student is the summation of the following two parts: (1) basic score, the grade of the student's coursework, and (2) research score, the equivalent score converted by the student's academic achievements (e.g., winning competitions, publishing papers and patents).

In practice, there are many factors to be considered in scholarship assignment. First, a scholarship from the same provider should not be assigned to the same student more than once, as sponsors require to cover as many deserving students as they can. Second, a scholarship cannot be further divided, as the amount of each scholarship is determined by its sponsor. Third, all scholarships must be awarded to students. Fourth, scholarships should be assigned to students based on their performances (scores gained from coursework and research), stating that the student with a higher score should receive an amount of scholarship no less than that received by students with lower scores. Fifth, the amount of scholarship assigned to each student should be strictly 
in line with his/her score, in order to guarantee equity of scholarship assignment. For instance, when two students get similar scores but the difference between the amounts of the scholarships awarded to these students is too large to ignore, such discrimination may lead to discontent as the students may feel unfairly treated.

Our personal experiences show that almost all scholarships are not directly assigned to students but awarded to the best applicants who apply for the scholarships. Students can separate their research scores into smaller parts and use different parts to apply for different scholarships. Then the applicants for each scholarship will be ranked by the summations of their basic scores and chosen research scores. The applicants with the highest rankings have higher chances of winning the scholarships. As we all know, the assignment mechanism is not only dependent on applicants' performances, but also strongly influenced by applicants' strategies. One can receive a higher amount of scholarships than students with higher scores by adopting a better strategy for dividing his/her research scores and applying for appropriate scholarships with fewer competitors. Moreover, such mechanism is both time- and energy-consuming for students as they tend to focus on collecting information of their competitors and developing appropriate application strategies at the expense of their studies and research, thus, exerts an overall negative impact on their academic performance. In this regard, it is imperative and of vital significance for university administrators to develop a systematic tool to assign scholarships in an efficient and equitable way.

1.1. Literature Review. It is reported in a diversity of researches that, in spite of providing financial assistance, scholarships will help students in various aspects including motivating studying, improving confidence, and even changing their future plans [4-6]. The assignment of scholarships thus becomes an important issue that might highly affect living and learning of graduate students. To the best of our knowledge, few researches have investigated the scholarship assignment problem, except the research conducted in [7]. Amorós et al. admitted that the best student should receive the most prestigious scholarship and proposed an assignment mechanism in Nash Equilibrium to achieve a socially optimal outcome. However, they fail to consider the equity norm in their assignment mechanism.

The equity norm has gained increasing attention in higher education [8-11] and is a pressing concern in the scholarship assignment as much as in other policy making [12-14] and resource or reward allocation problems [1519]. Equity, unlike equality which implies that all members should be assigned to equal amount of resource, requires that the allocated resource should be proportionate to the magnitude of each member's contribution [20,21]. In a group, the members who perform better often require equity when assigning resources. It is found that people who outperform their peers intend to ask for equity in resource allocation [22]. Such mechanism implies that, in the scholarship assignment, students with higher scores might possess greater demands for equity. Therefore, it is important to consider the equity norm in scholarship assignment.
As few efforts have focused on the equity concern of scholarship assignment problem, this research aims to develop a scholarship assignment model to optimize the quality of scholarship assignment scheme by considering the equity norm. The model can guarantee a basic requirement for equity; i.e., students receive a higher amount of scholarships only when they have higher scores. Further, this proposed model can quantify the equity of all feasible assignment schemes satisfying the above requirement and help select the scheme with the highest equity.

1.2. Objectives and Contributions. The objective of this research is to develop an efficient tool to generate the assignment scheme of scholarships with the highest equity. The contribution of the paper is threefold. First, we develop a new approach that allows the university administrators to assign scholarships to students according to the ranking of coursework and research performances. This is because our method prioritizes students with higher scores in scholarship assignment. As a result, the equity of scholarship assignment scheme can be guaranteed by meeting the requirement that a student with a higher score must receive an amount of scholarships no less than students with lower scores. Such equity requirement, however, is hard to satisfy when students take the leading role in scholarship assignment process, as if scholarships should be applied by students. On the contrary, the proposed method is led by university administrators, which contributes to helping motivate and encourage the students to work hard in their study and research, as better performances are strictly associated with higher monetary rewards.

Second, as this assignment is done by university administrators instead of students themselves, who are naturally busy with studying, researching, and other commitments, our method can save the valuable time for students.

Third, the method can assess the equity of different feasible assignment schemes. Various schemes can meet the requirement that better students receive more scholarships, while the qualities of schemes differ from each other. One may find that another student who performs little better than s/he can receive much more scholarships, which is another form of inequity. This concern can be addressed by introducing the Gini coefficient to measure the inequity of each feasible scholarship assignment scheme.

The remainder of this paper is organized as follows. The description of considerations in the scholarship assignment problem is first introduced. The method and solution algorithm to solve the proposed scholarship assignment problem are presented in detail, followed by a small example to illustrate the application of the proposed method. Then the results and findings of the numerical example are reported. Finally, the conclusion is drawn.

\section{The Scholarship Assignment Problem}

This study investigates the assignment mechanism of scholarships at a department. In a department, different kinds of scholarships are offered to graduate students who have done excellent jobs in academic research. Different types 
of scholarships may differ from each other in two aspects: (1) the number of awardees and (2) the amount of money an awardee can receive. Students are free to apply for different scholarships. The results of scholarship appraisal are dependent on the students' scores they have obtained in the previous year. As mentioned above, the total score of a student is composed of the basic score obtained from coursework and additional research scores based on his academic achievements such as published journal papers. In order to simplify the evaluation of students' works, the basic score is measured in the hundred-mark system, while different kinds of academic achievements are measured in the same weight. Additionally, a standardization process is applied to convert a specific work into standard scores. For instance, the score of a published paper can be calculated in terms of two components: journal's impact factor (IF) ranking and author's order. A student who has published a paper in the journal which occupies in Q1 [23] and is also the first author of that journal will achieve additional 10 points. The score decreases linearly with the slip of IF or author's order.

In this study, we assume that the department is in charge of the assignment of scholarships and the scholarship is allocated according to the ranking of students' total scores. To avoid the unfairness in assigning scholarships, we include the constraint that the student with a higher score should be offered at least no less amount of scholarship than students with lower scores. Meanwhile, other practical constraints are considered in the study. For instance, a single scholarship cannot be shared by different students; a student can only be awarded by a certain type of scholarship no more than once; a student can either fail to win any scholarship or win multiple scholarships; all the scholarships should be assigned to students. The optimal assignment should be the scheme that best guarantee the amount of scholarship received by a student is proportionate to the magnitude of his/her total score.

The notations used in the method are listed below:

Sets

\section{$J$ : Set of scholarships}

I: Set of students

$J_{i}$ : Set of remaining scholarships that can be assigned to student $i$

\section{Indices}

$j:$ An index $j \in J$ that refers to a particular scholarship $i, k$ : Indices $i, k \in I$ that refer to particular students

\section{Parameters and Variables}

$m_{j}$ : The amount of scholarship $j(\$)$

$c_{j}$ : The number of scholarship $j$

$e_{j}$ : Equivalent score of scholarship $j$

$s_{i}$ : The score of student $i$

$v$ : Monetary value of a unit score

\author{
G: Gini coefficient \\ $n$ : Number of students \\ $W_{i}$ : Welfare of student $i$ \\ $\bar{W}$ : Average welfare of individual students \\ $W_{\min }$ : Minimum welfare of students \\ $\kappa:$ A constant used to adjust individual welfare \\ $W_{i}^{s}$ : Adjusted welfare of student $i$ \\ $\bar{W}^{s}$ : Adjusted average welfare of individual students \\ $\delta_{i j}$ : A binary decision variable which equals 1 if \\ scholarship $j$ is assigned to student $i$, and 0 otherwise
}

\section{The Scholarship Assignment Mechanism}

The scholarship assignment problem discussed above can be deemed as a combination of two subproblems. The first subproblem is to search for all feasible assignment schemes which meet the practical constraints and the basic equity requirement simultaneously. The second subproblem is to quantify the equity of each feasible scheme and select the optimal scheme with the highest equity.

To address the first subproblem, a method composed of knapsack subproblems is developed to assign scholarships to students in sequence. In the knapsack subproblem, the total score gained by each student is deemed as the knapsack and the equivalent score of each scholarship is regarded as the item to be put in the knapsack. Given a certain value of a unit score, the amounts of all scholarships can be converted to equivalent scores. Assigning scholarships to each student by solving knapsack problems can guarantee that the amount of scholarships (equivalent score) awarding to a student is the maximum one that can be allocated to him/her among remaining scholarships. Hence, the students who have priorities in such scholarship assignment process can receive more scholarships. Through ranking students according to their scores and assigning scholarships in sequence, the proposed method thus certainly satisfies the basic equity requirement that students with higher scores should receive higher amounts of scholarships.

To address the second subproblem, the Gini coefficient is introduced to measure the inequity of each feasible solution. The Gini coefficient can quantify the equity of distribution of welfare (difference between the actual and ideal amount of scholarship gained by each individual student). The Gini coefficient equals 0 when students receive the same welfare; i.e., there exists no difference between the actual and ideal amounts of scholarship gained by each student. A higher Gini coefficient is associated with a higher inequity of the investigated assignment scheme. The proposed method modifies the original calculation of Gini coefficient used in the field of economics, making it applicable to the scholarship assignment problem. The feasible assignment scheme with the lowest value of Gini coefficient is selected as the optimal assignment scheme.

3.1. Searching for Feasible Solutions. To satisfy the requirement that students with higher scores can obtain an amount 
of scholarships no less than students with lower scores, the scholarship assignment problem is converted to a series of one-dimensional 0-1 knapsack problems [24, 25].

Firstly, the initial monetary value $v$ of a unit score can be calculated by

$$
v=\frac{\sum_{j \in J} m_{j} \cdot c_{j}}{\sum_{i \in I} s_{i}} .
$$

According to the monetary value of a unit score, the amount of scholarships, $m_{j}$, can then be converted to equivalent scores, $e_{j}$. The process can be expressed as

$$
e_{j}=\frac{m_{j}}{v}, \quad \forall j \in J
$$

The sequence of assigning scholarships to students is in accordance with the ranking of students' scores. In each iteration, the scholarships are allocated to the student with the highest score among unsigned students, and the amount of scholarships to be allocated to the student is derived through solving a knapsack subproblem. Let the score of a student $i, s_{i}$, be the capacity of the knapsack, and the equivalent score of scholarship $j, e_{j}$, be the items to be put into the knapsack. Thus the scholarship assignment scheme of the chosen student $i$ can be derived from

$$
\begin{aligned}
\max & \sum_{j \in J_{i}} e_{j} \cdot \delta_{i j} \\
\text { s.t. } & \sum_{j \in J_{i}} e_{j} \cdot \delta_{i j} \leq s_{i} .
\end{aligned}
$$

By iteratively solving knapsack subproblems for each chosen student and assigning scholarships in accordance to the solutions, the students with higher scores, who possess priority in the scholarship assignment, can certainly obtain greater amounts of scholarships. Hence, given a certain monetary value of the score $v$, we can derive a corresponding feasible solution set (scholarship assignment scheme) using the above method. By iteratively adjusting the monetary value of a unit score, we can enumerate all the feasible solution sets.

However, the qualities of feasible solution sets derived by the above method cannot be judged. As this paper aims to assign scholarships to students considering the equity norm, the finally selected assignment scheme must be the one with the highest equity. The following section introduces the method to quantify equity of each feasible solution.

\subsection{Measuring Equity of Scholarship Assignment Scheme.} Note that perfect equity means that every student can receive a proportion of scholarship same as the proportion of his/her score in the total score. To quantify the equity of scholarship assignment schemes which aim to assigning different scholarships to a group of students with different scores, a suggestion is associated with modifying an existing metric of income inequity, i.e., Gini coefficient. In the transportation field, the Gini coefficient is widely utilized to analyze inequity in accessibility [26-28] and effect of transport policies [29, 30]. Herein, the Gini coefficient is adopted to measure the social welfare (for instance, the accessibility to certain opportunities or the welfare of toll pricing scheme) achieved by transport users. In scholarship assignment, the Gini coefficient $G$ can express an inequality metric that evaluates the departure from perfect equity, which can be expressed as

$$
G=\frac{1}{2 n^{2} \bar{W}} \sum_{i \neq k \in I}\left|W_{i}-W_{k}\right|
$$

where $W_{i}$ denotes the benefit that student $i$ receives from the actual assignment scheme, $\bar{W}$ denotes the average individual welfare, and $n$ is the number of students. Considering the practical constraints, the ideal assignment result with perfect equity is hard to reach. An individual student might gain either positive benefit (receive more scholarship than s/he deserves) or negative benefit (receive less scholarship than s/he deserves) in certain scholarship assignment scheme. To measure the benefit each student receives from the assignment scheme, we define the welfare of student $i, W_{i}$, as the difference between the student's actual scholarship and ideal scholarship, which can be derived by

$$
W_{i}=s_{i}^{a}-s_{i}^{p}
$$

where $s_{i}^{a}$ and $s_{i}^{p}$ denote the actual and ideal results of scholarship assignment with regards to student $i$ respectively. The average individual welfare $\bar{W}$ can be expressed as

$$
\bar{W}=\frac{\sum_{i \in I} W_{i}}{n} .
$$

It is evident that the average individual welfare $\bar{W}$ equals 0 , and the individual welfare can be negative. These properties prohibit the usage of original Gini coefficient in that the value of average and individual income used in the original Gini coefficient evaluation can only be positive. Therefore, a rescaling process is necessary to implement (5). The re-scaled individual welfare $W_{i}^{s}$ can be derived by

$$
W_{i}^{s}=W_{i}+\left|W_{\min }\right|+\kappa
$$

where $W_{\text {min }}$ denotes the minimum individual welfare and $\kappa$ is a given constant.

By using $W_{i}^{s}$ to replace $W_{i}$ in (5) and (7), the Gini coefficient $G$ of each solution can be obtained:

$$
G=\frac{1}{2 n^{2} \bar{W}^{s}} \sum_{i \neq k \in I}\left|W_{i}^{s}-W_{k}^{s}\right| .
$$

\section{Solution Algorithm}

As discussed in Section 3, the task of searching for feasible assignment scheme can be converted to a series of onedimensional 0/1 knapsack problem, which can be exactly solved by dynamic programming algorithms [31-36]. In this section, a solution algorithm for the knapsack subproblem based on dynamic programming is used to find the optimal scholarship assignment for each student in sequence. On the basis of it, a solution algorithm for finding feasible assignment schemes and selecting the optimal scheme is proposed. 
4.1. Algorithm 1: Algorithm for One-Dimensional 0-1 Knapsack Subproblem. Assuming there are totally $p$ types of scholarships, let stage $h$ denote the first $h$ types of scholarships that are considered in scholarship assignment; $s$ denote the equivalent score that is currently assigned to the selected student; and $f_{h}(s)$ denote the maximum equivalent score the selected student can obtain at stage $h$.

Step 1 (initialization). Set $f_{0}(s)=0, \forall s \leq s_{i}, h=1, s=0$, $j=1$.

Step 2. Update $f_{h}(s)$.

Step 2.1. $f_{h}(s)=\max \left\{f_{h-1}(s), f_{h-1}\left(s-m_{i}\right)+m_{j}\right\}$, where $m_{i}$ is the equivalent score of the scholarship previously assigned to the selected student.

Step 2.2. $j=j+1$. If $j>h$, go to Step 2.3; otherwise, go to Step 2.1

Step 2.3. $s=s+1$. If $s>s_{i}$, go to Step 3; otherwise, go to Step 2.1.

Step 3. $h=h+1$. If $h \leq p$, go to Step 2; otherwise, return $f_{h-1}\left(s_{i}\right)$ and stop the algorithm.

\subsection{Algorithm 2: Derive Feasible Schemes and Select Optimal Scheme}

Step 1. Initialize the monetary value of a unit score $v$ using (1); set the value of step size $d$ and upper bound of monetary score value $v_{\max }$.

Step 2. Obtain the equivalent score of each scholarship $m_{j}$ using (2).

Step 3. Derive feasible scholarship assignment.

Step 3.1. Rank students according to their scores and put students into set $\mathrm{R}\{1,2, \ldots, i, \ldots\}$.

Step 3.2. Assign scholarships to the first student $\mathrm{i}$ in set $\mathrm{R}$ using Algorithm 1.

Step 3.3. Delete student $i$ from set R. If set $\mathrm{R}$ is not empty, $i=i+1$, go to Step 3.2; otherwise, go to Step 4 .

Step 4. Store assignment result of Step 3. Increase monetary score value $v=v+d$; if $v<v_{\max }$, go to Step 2; otherwise, go to Step 5.

Step 5. Using (9) to calculate the Gini coefficient of each assignment scheme stored in Step 4, return the optimal assignment scheme with lowest Gini coefficient value.

\section{An Illustrative Example}

To illustrate the proposed method, we propose a small case with 3 types of scholarships and 5 candidates as an example. The unit of scholarship is US dollar (\$) in Tables 1, 3, and 4.
TABLE 1: Details of scholarships.

\begin{tabular}{lcc}
\hline ID & Number of awardees & Amount of scholarship \\
\hline 1 & 2 & 8000 \\
2 & 3 & 5000 \\
3 & 1 & 10000 \\
\hline
\end{tabular}

TABLE 2: Data of candidates.

\begin{tabular}{lc}
\hline ID & Score \\
\hline 1 & 25 \\
2 & 20 \\
3 & 30 \\
4 & 35 \\
5 & 15 \\
\hline
\end{tabular}

TABLE 3: Ideal assignment results.

\begin{tabular}{lc}
\hline ID & Amount of scholarship \\
\hline 1 & 8200 \\
2 & 6560 \\
3 & 9840 \\
4 & 11480 \\
5 & 4920 \\
\hline
\end{tabular}

Tables 1 and 2 show the details of scholarships and scholarship candidates.

It can be seen that the number of awardees of each scholarship is separately 2, 3, and 1; the monetary awards provided by each scholarship are, respectively, $\$ 8000,5000$, and 10000. The total scores of each student are 25, 20,30 35 , and 15 . Following the equity norm that the ideal amount of scholarship received by each student is proportionate to his/her score, the ideal assignment result neglecting the practical constraints is shown in Table 3.

Using the method discussed in Section 3.1, four feasible schemes can be obtained by iteratively solving the knapsack subproblem for each student and then adjusting the monetary value of the score. Note that the derived schemes only satisfy the basic equity requirement that a student with higher score must receive an amount of scholarship no less than that received by students with comparatively lower scores. The details regarding the 4 schemes are shown in Table 4.

Through the method described in Section 3.2, we can then compute the Gini coefficient of each scheme, which is shown in Table 5.

As per the Gini coefficients of each scheme, it can be found that, among 4 feasible schemes, scheme 1 is the one with the highest equity, as the Gini coefficient of scheme 1 is the lowest. Therefore, scheme 1 is chosen as the final scholarship assignment scheme in this numerical example.

From this example, it can be concluded that the proposed method can enumerate several feasible scholarship assignment schemes and then choose the optimal one with the minimum value of Gini coefficient. This demonstrates the practical relevance of the proposed method. 
TABLE 4: Derived feasible schemes of scholarship assignment.

\begin{tabular}{|c|c|c|c|c|c|c|c|}
\hline \multicolumn{4}{|c|}{ Scheme 1} & \multicolumn{4}{|c|}{ Scheme 2} \\
\hline ID & Score & $\begin{array}{l}\text { Amount of } \\
\text { scholarship }\end{array}$ & $\begin{array}{c}\text { Type of } \\
\text { scholarship }\end{array}$ & ID & Score & $\begin{array}{l}\text { Amount of } \\
\text { scholarship }\end{array}$ & $\begin{array}{c}\text { Type of } \\
\text { scholarship }\end{array}$ \\
\hline 1 & 25 & 8000 & 1 & 1 & 25 & 8000 & 1 \\
\hline 2 & 20 & 5000 & 2 & 2 & 20 & 5000 & 2 \\
\hline 3 & 30 & 10000 & 3 & 3 & 30 & 13000 & 1,2 \\
\hline 4 & 35 & 13000 & 1,2 & 4 & 35 & 15000 & 1,3 \\
\hline 5 & 15 & 5000 & 2 & 5 & 15 & 0 & 1 \\
\hline \multicolumn{4}{|c|}{ Scheme 3} & \multicolumn{4}{|c|}{ Scheme 4} \\
\hline ID & Score & $\begin{array}{l}\text { Amount of } \\
\text { scholarship }\end{array}$ & $\begin{array}{c}\text { Type of } \\
\text { scholarship }\end{array}$ & ID & Score & $\begin{array}{l}\text { Amount of } \\
\text { scholarship }\end{array}$ & $\begin{array}{c}\text { Type of } \\
\text { scholarship }\end{array}$ \\
\hline 1 & 25 & 5000 & 2 & 1 & 25 & 5000 & 2 \\
\hline 2 & 20 & 5000 & 2 & 2 & 20 & 0 & 1 \\
\hline 3 & 30 & 13000 & 1,2 & 3 & 30 & 13000 & 1,2 \\
\hline 4 & 35 & 18000 & 1,3 & 4 & 35 & 23000 & $1,2,3$ \\
\hline 5 & 15 & 0 & 1 & 5 & 15 & 0 & 1 \\
\hline
\end{tabular}

TABle 5: Gini coefficients of each scheme.

\begin{tabular}{lc}
\hline Scheme & Gini coefficient \\
\hline 1 & 0.334 \\
2 & 0.351 \\
3 & 0.475 \\
4 & 0.540 \\
\hline
\end{tabular}

\section{Conclusion}

This paper develops a method to derive the optimal scholarship assignment scheme with the highest equity for university administrators. The method is applicable as (1) it meets the equity requirement that students who perform better ought to receive scholarships equal to or more than those received by less-achieving students; (2) the scholarship assignment eliminates the need of students to manually apply for specific scholarships, which is a time- and energy-consuming process; and (3) the equity of derived assignment schemes can be quantified through the Gini coefficient, and the scheme with the maximum equity (minimum Gini coefficient value) can be identified and selected. An illustrative example is adopted to show the applicability of the proposed method. The results indicate that the proposed method can obtain a set of feasible assignment schemes efficiently and then derive the optimal one with the highest equity.

\section{Data Availability}

The hypothetical data used to support the findings of this study are included within the article. No external data were used to support this study.

\section{Conflicts of Interest}

The authors declare that they have no conflicts of interest.

\section{Acknowledgments}

This study is supported by the Top-Notch Academic Programs Project of Jiangsu Higher Education Institutions (PPZY2015B148) and the Project of Educational Reform and Practice in Southeast University (2017-071).

\section{References}

[1] P. E. Peterson, D. Myers, and W. G. Howell, An Evaluation of the New York City School Choice Scholarships Program: The First Year, Mathematica Policy Research, Washington, DC, USA, 1998.

[2] S. L. Desjardins, "The impact of Washington State Achievers Scholarship on student outcomes," in Annual meeting of Association for the Study of Higher Education, Vancouver, BC, Canada, 2009.

[3] S. L. DesJardins and B. P. McCall, "The impact of the Gates Millennium Scholars Program on college and post-college related choices of high ability, low-income minority students," Economics of Education Review, vol. 38, no. 1, pp. 124-138, 2014.

[4] M. R. Anderson-Rowland, "Evaluation of a ten year life planning assignment for an academic scholarship success class," in Proceedings of the 41st Annual Frontiers in Education Conference: Celebrating 41 Years of Monumental Innovations from Around the World, FIE 2011, pp. 1-7, 2012.

[5] A. Porter, R. Yang, J. Hwang, J. McMaken, and J. Rorison, “The Effects of Scholarship Amount on Yield and Success for Master's Students in Education," Journal of Research on Educational Effectiveness, vol. 7, no. 2, pp. 166-182, 2014.

[6] H. Forsyth and A. Cairnduff, "A scholarship of social inclusion in higher education: why we need it and what it should look like," Higher Education Research \& Development, vol. 34, no. 1, pp. 219-222, 2015.

[7] P. Amorós, L. C. Corchón, and B. Moreno, "The scholarship assignment problem," Games \& Economic Behavior, vol. 38, no. 1, pp. 1-18, 2002.

[8] G. Goastellec, "Globalization and implementation of an equity norm in higher education: Admission processes and funding 
framework under scrutiny," Peabody Journal of Education, vol. 83, no. 1, pp. 71-85, 2008.

[9] W. O. Lee and M. Manzon, "The issue of equity and quality of education in Hong Kong," The Asia-Pacific Education Researcher, vol. 23, no. 4, pp. 823-833, 2014.

[10] T. Pitman, "Unlocking the gates to the peasants: are policies of 'fairness' or 'inclusion' more important for equity in higher education?" Cambridge Journal of Education, vol. 45, no. 2, pp. 281-293, 2015.

[11] X. Qu, W. Yi, T. Wang, S. Wang, L. Xiao, and Z. Liu, "Mixedinteger linear programming models for teaching assistant assignment and extensions," Scientific Programming, vol. 2017, Article ID 9057947, 7 pages, 2017.

[12] Z. Liu, S. Wang, and Q. Meng, "Optimal joint distance and time toll for cordon-based congestion pricing," Transportation Research Part B: Methodological, vol. 69, pp. 81-97, 2014.

[13] Z. Liu, S. Wang, W. Chen, and Y. Zheng, "Willingness to board: a novel concept for modeling queuing up passengers," Transportation Research Part B: Methodological, vol. 90, pp. 7082, 2016.

[14] Z. Liu, S. Wang, B. Zhou, and Q. Cheng, "Robust optimization of distance-based tolls in a network considering stochastic day to day dynamics," Transportation Research Part C: Emerging Technologies, vol. 79, pp. 58-72, 2017.

[15] E. A. Mannix, M. A. Neale, and G. B. Northcraft, "Equity, equality, or need? The effects of organizational culture on the allocation of benefits and burdens," Organizational Behavior and Human Decision Processes, vol. 63, no. 3, pp. 276-286, 1995.

[16] S. Wang, "Efficiency and equity of speed limits in transportation networks," Transportation Research Part C: Emerging Technologies, vol. 32, pp. 61-75, 2013.

[17] S. Wang, Q. Meng, and Z. Liu, "Containership scheduling with transit-time-sensitive container shipment demand," Transportation Research Part B: Methodological, vol. 54, pp. 68-83, 2013.

[18] L. Anselmi, M. Lagarde, and K. Hanson, "Going beyond horizontal equity: An analysis of health expenditure allocation across geographic areas in Mozambique," Social Science \& Medicine, vol. 130, pp. 216-224, 2015.

[19] S. Caleo, "When distributive justice and gender stereotypes coincide: Reactions to equity and equality violations," Journal of Applied Social Psychology, vol. 48, no. 5, pp. 257-268, 2018.

[20] J. S. Adams, "Inequity in social exchange," Advances in Experimental Social Psychology, vol. 2, no. 4, pp. 267-299, 1965.

[21] E. Walster, G. Walster, and E. Berscheid, Equity: Theory and Research, Allyn \& Bacon, Boston, MA, USA, 1978.

[22] D. M. Messick and K. P. Sentis, "Fairness and preference," Journal of Experimental Social Psychology, vol. 15, no. 4, pp. 418434, 1979.

[23] ISI (Institute for Scientific Information), "Data from: Journal Citation Reports" (Dataset). Clarivate Analytics. Accessed July 20, 2018, http://jcr.incites.thomsonreuters.com/ JCRJournalHomeAction.action?.

[24] S. Martello and P. Toth, "Algorithms for Knapsack problems," North-Holland Mathematics Studies, vol. 132, pp. 213-257, 1987.

[25] H. M. Salkin and K. C. A. De, "The knapsack problem: A survey," Naval Research Logistics, vol. 22, no. 1, pp. 127-144, 2010.

[26] T. Neutens, "Accessibility, equity and health care: Review and research directions for transport geographers," Journal of Transport Geography, vol. 43, pp. 14-27, 2015.
[27] H. R. Waters, "Measuring equity in access to health care," Social Science \& Medicine, vol. 51, no. 4, pp. 599-612, 2000.

[28] T. F. Welch and S. Mishra, "A measure of equity for public transit connectivity," Journal of Transport Geography, vol. 33, no. 33, pp. 29-41, 2013.

[29] A. Sumalee, "Optimal toll ring design with equity constraint: An evolutionary approach," Journal of Eastern Asia Society for Transportation Studies, vol. 5, pp. 1813-1828, 2003.

[30] X. Sun, Z. Liu, and S. Chen, "The Equity Issue for Cordon-Based Congestion Pricing with Distance Toll," in Proceedings of the 2nd International Conference on Vulnerability and Risk Analysis and Management, ICVRAM 2014, pp. 2310-2319, July 2014.

[31] S. Martello, D. Pisinger, and P. Toth, "Dynamic programming and strong bounds for the 0-1 Knapsack Problem," Management Science, vol. 45, no. 3, pp. 414-424, 1999.

[32] P. Toth, "Dynamic programming algorithms for the Zero-One Knapsack problem," Computing, vol. 25, no. 1, pp. 29-45, 1980.

[33] D. Pisinger, "A minimal algorithm for the 0-1 knapsack problem," Operations Research, vol. 45, no. 5, pp. 758-767, 1997.

[34] F. Li, Z. L. Chen, and L. Tang, "Integrated Production, Inventory and Delivery Problems: Complexity and Algorithms," INFORMS Journal on Computing, vol. 29, no. 2, pp. 232-250, 2017.

[35] H. Liu and D. Z. W. Wang, "Locating multiple types of charging facilities for battery electric vehicles," Transportation Research Part B: Methodological, vol. 103, pp. 30-55, 2017.

[36] J. Chen, S. Wang, Z. Liu, and Y. Guo, "Network-based optimization modeling of manhole setting for pipeline transportation," Transportation Research Part E: Logistics and Transportation Review, vol. 113, pp. 38-55, 2018. 


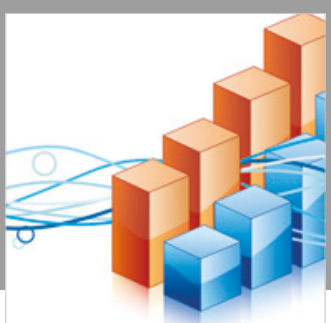

Advances in

Operations Research

\section{-n-m}
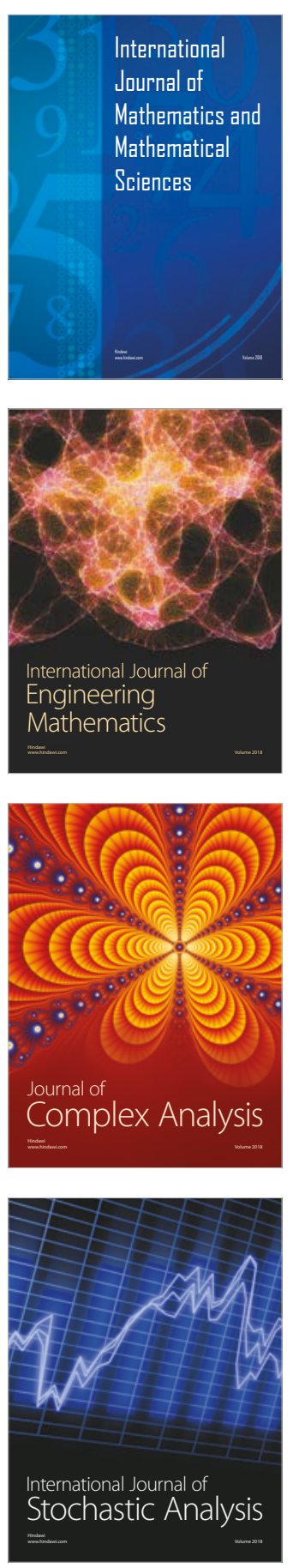
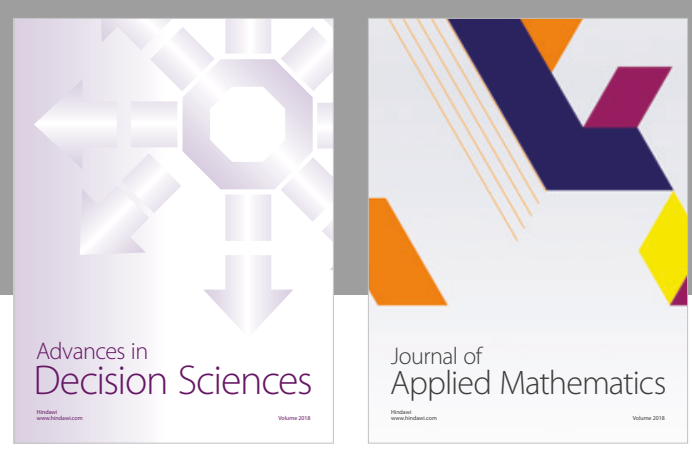

Journal of

Applied Mathematics
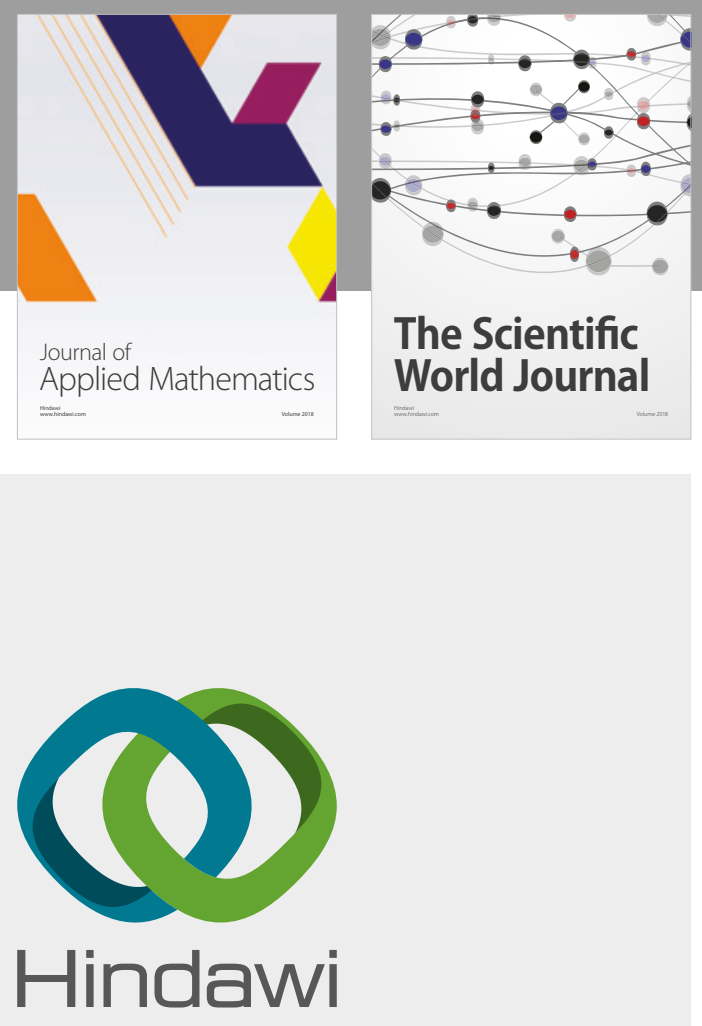

Submit your manuscripts at

www.hindawi.com

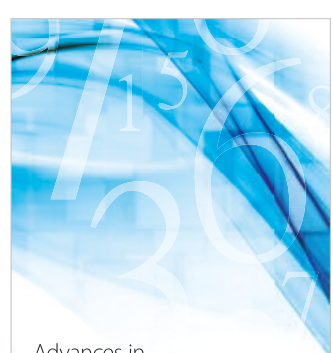

Advances in
Numerical Analysis
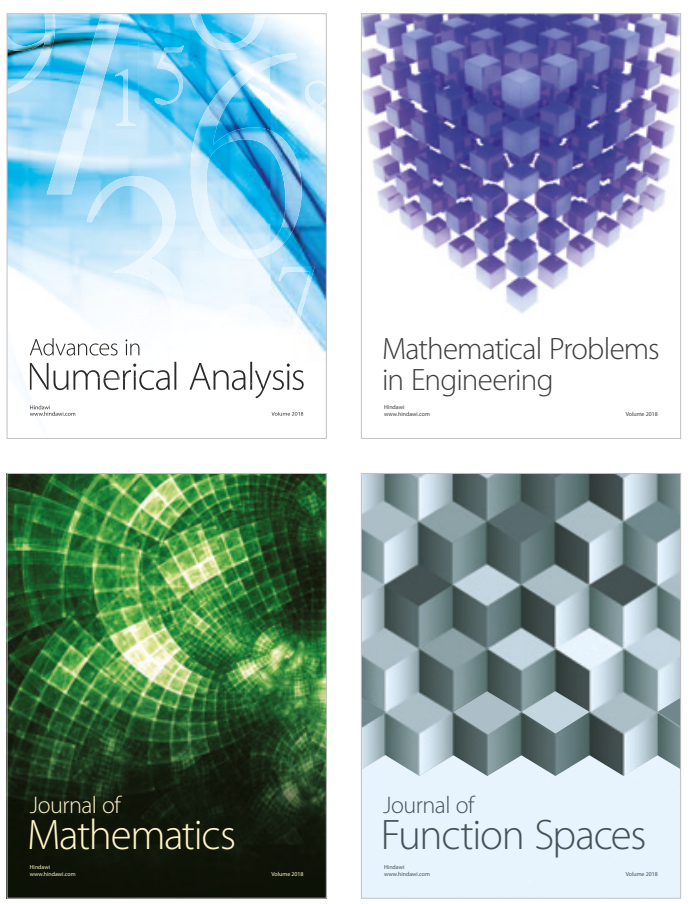

Mathematical Problems in Engineering

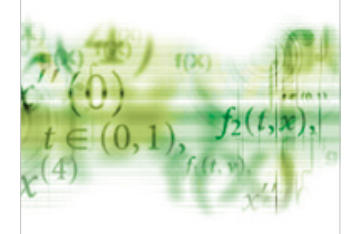

International Journal of

Differential Equations

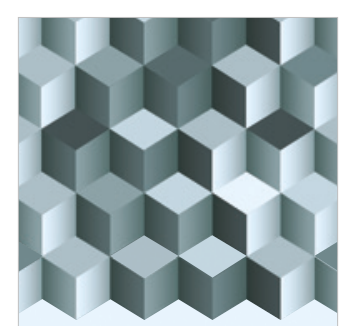

Journal of

Function Spaces

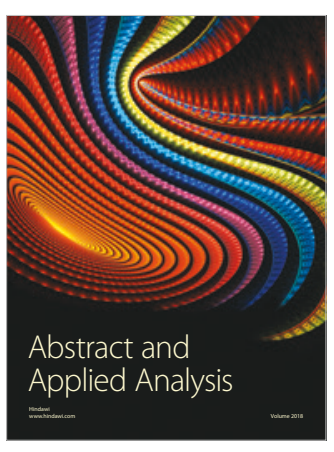

The Scientific

World Journal

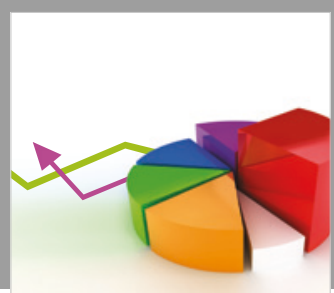

Journal of

Probability and Statistics
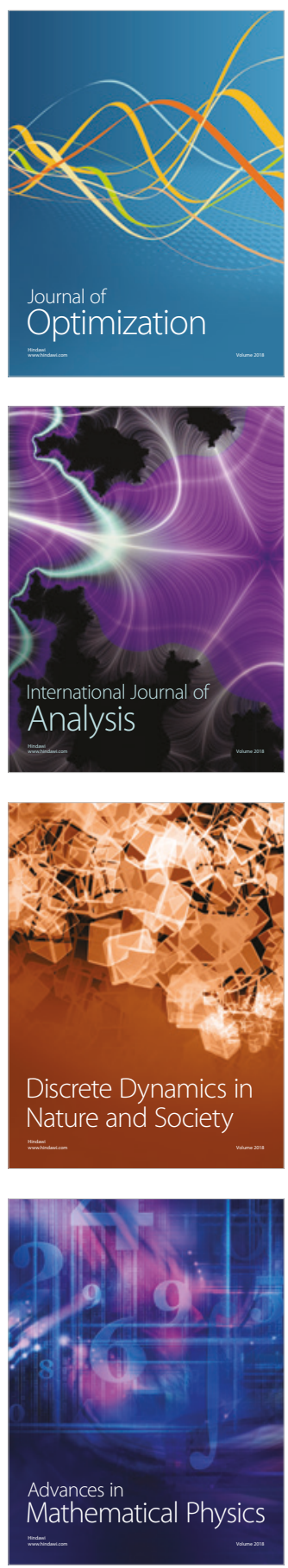